\title{
Alternatif Penggunaan Tertinggi dan Terbaik pada Lahan Pasar Blauran Surabaya
}

\author{
Mifta Afiata dan Christiono Utomo \\ Jurusan Teknik Sipil, Fakultas Teknik Sipil dan Perencanaan, Institut Teknologi Sepuluh Nopember (ITS) \\ Jl. Arief Rahman Hakim, Surabaya 60111 Indonesia \\ e-mail: christiono@ce.its.ac.id; mita.afiata21@gmail.com
}

\begin{abstract}
Abstrak-Aktifitas perdagangan salah satunya terjadi di Pasar tradisional. Kondisi pasar yang sepi pengunjung dan banyaknya pembeli yang lebih memilih pusat perbelanjaan modern membuat pasar tradisional semakin ditinggalkan. Salah satunya adalah pasar Blauran Surabaya. Pasar Blauran merupakan pasar tradisional yang terletak di Jalan Kranggan Sawahan Surabaya dengan luas $5550 \mathrm{~m}^{2}$. Lokasi sekitar pasar yang sudah banyak berkembang menjadi properti komersil, sedangkan kondisi pasar yang kurang nyaman, panas, tidak tersedianya lahan parkir dan bangunannya yang sudah tua. Oleh karena itu lahan Pasar Blauran Surabaya perlu ditinjau penggunaan lahannya agar dapat memberikan nilai lahan tertinggi. Analisa yang digunakan dalam penelitian ini terdiri dari aspek legal, fisik, finansial dan produktivitas maksimum. Berdasarkan penyebaran kuisioner kepada stakeholder didapatkan alternatif yaitu Revitalisasi Pasar, Mixed use Pasar dengan Pusat Perbelanjaan dan Mixed use Pasar dengan Perkantoran. Hasil analisa perhitungan, alternatif dengan nilai lahan tertinggi dan produktifitas maksimum yaitu mixed use pasar dan perbelanjaan dengan nilai lahan sebesar $\mathbf{R p}$ 71.575.064,- dan produktifitas lahan sebesar $236,07 \%$ dari nilai lahan awal.
\end{abstract}

Kata kunci : Penggunaan Tertinggi dan Terbaik, Lahan Pasar Blauran, Properti Komersil.

\section{LATAR BELAKANG}

urabaya merupakan kota dengan potensi pertumbuhan Sinfrastruktur, perekonomian dan bisnis yang sangat $N_{\text {pesat. Perdagangan merupakan salah satu penunjang }}$ kegiatan perekonomian. Aktifitas perdagangan salah satunya terjadi di pasar tradisional. Kondisi pasar yang sepi pengunjung dan banyaknya pengunjung yang lebih memilih pusat perbelanjaan modern ini yang membuat pasar tradisional semakin ditinggalkan, salah satunya adalah Pasar Blauran Surabaya.

Pasar ini berada di lokasi strategis, berada di pusat kota dan dekat dengan kawasan Tunjungan Surabaya. Lokasi di sekitar pasar blauran sudah banyak berkembang menjadi properti komersil seperti Hotel 88, Hotel Amaris, BG Junction, Ballroom Empire Palace, Siola Surabaya dan pertokoan lainnya. Kondisi pasar tidak terawat, bangunan yang sudah tua, dan banyaknya kios pedagang yang tutup menjadikan pasar Blauran kurang layak jika terus saja dibiarkan begitu saja. Oleh karena itu lahan pasar blauran perlu dianalisa penggunaan lahannya agar dapat digunakan semaksimal mungkin.

Analisa penggunaan lahan pada Pasar Blauran Surabaya menggunakan analisa penggunaan tertinggi dan terbaik yang terdiri dari beberapa aspek kriteria yaitu diizinkan oleh peraturan yang ada, memungkinkan secara fisik untuk dibangun, layak secara finansial dan memiliki produktifitas lahan maksimum [1]

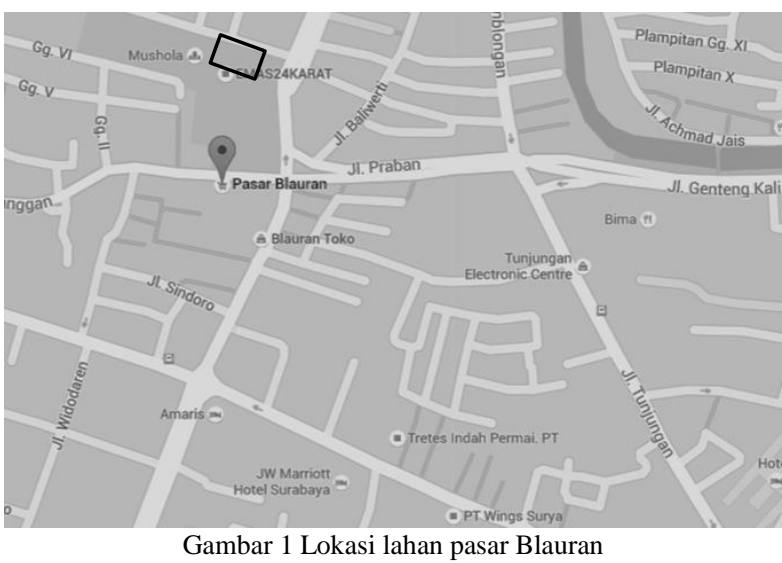

\section{PENELITIAN TERDAHULU}

Penelitian [2] dan [5] memiliki persamaan berupa objek penelitian yang merupakan objek dengan lahan kosong. Lahan tersebut dianalisa penggunaannya untuk dijadikan properti komersil. Penelitian tersebut hanya berbeda pada lokasi lahan dan memiliki persamaan berupa letak lahan yang berada di tengah kota. Penelitian [3] dan [6] mengambil objek penelitian lahan yang telah difungsikan menjadi bangunan gedung Serbaguna Purnama dan Trillium Office and Residence lalu dianalisa untuk mengetahui penggunaan terbaik dan tertinggi dari lahan yang telah digunakan. Sedangkan pada penelitian [4] mengambil objek lahan yang sudah tidak difungsikan lagi sebagai SPBU Biliton dan dianalisa untuk dijadikan properti komersil.

Beberapa penelitian terdahulu memiliki persamaan dan perbedaan dalam hal uji kelayakan aspek finansialnya. Penelitian yang telah dilakukan oleh [2] [3] dan [6] menggunakan uji kelayakan pada aspek finansial berupa NPV. Pada penelitian [4] menggunakan NOI dan Profibilitas Index pada uji kelayakannya sedangkan penelitian [5] hanya menggunakan NOI sebagai uji kelayakan aspek finansialnya.

Berdasarkan beberapa penelitian terdahulu terdapat persamaan dalam hal metode analisa yang digunakan yaitu menggunakan analisa pada aspek legal, fisik, finansial dan produktifitas maksimum. Sedangkan perbedaan penelitian terdahulu dengan penelitian pada Tugas Akhir ini berupa objek lahan yang diteliti. Pada penelitian [3] dan [6] objek lahan yang digunakan adalah lahan yang telah difungsikan menjadi bangunan berupa gedung Serbaguna Purnama dan Trillium Office and Residence. Sedangkan pada penelitian tugas akhir ini objek penelitian berupa lahan Pasar Blauran. Pada analisa tugas akhir ini lahan objek penelitian direncanakan sebagai lahan kosong dikarenakan kondisi bangunan yang sudah tua dan kurang terawat dengan baik. 


\section{METODOLOGI}

Penelitian ini menggunakan analisa penggunaan tertinggi dan terbaik untuk menganalisa objek lahan yang ditinjau. Analisa ini terdiri dari variabel penelitian yang dapat dilihat pada Tabel 1.

Tabel 1.

Variabel dan klasifikasi analisa data

\begin{tabular}{|c|c|c|c|c|}
\hline & Variabel & Klasifikasi & Jenis Data & Sumber Data \\
\hline & $\begin{array}{l}\text { Penentuan } \\
\text { Alternatif }\end{array}$ & $\begin{array}{l}\text { Alternatif } \\
\text { penggunaan lahan } \\
\text { Pasar Blauran } \\
\text { Surabaya }\end{array}$ & Data Primer & $\begin{array}{l}\text { Wawancara dan } \\
\text { pembagian kuesioner } \\
\text { kepada Stakeholder } \\
\text { yang berkaitan } \\
\text { dengan Pasar Blauran }\end{array}$ \\
\hline 2. & Aspek Legal & $\begin{array}{l}\text { a. Keperuntukan } \\
\text { lahan } \\
\text { b. Building Code } \\
\text { terdiri dari GSB, } \\
\text { KDB, KLB, } \\
\text { KDH }\end{array}$ & $\begin{array}{l}\text { Data } \\
\text { Sekunder }\end{array}$ & $\begin{array}{l}\text { Dinas Cipta Karya } \\
\text { dan Tata Ruang Kota } \\
\text { Surabaya }\end{array}$ \\
\hline 3. & Aspek Fisik & $\begin{array}{l}\text { a. Lokasi lahan } \\
\text { b. Bentuk dan } \\
\text { ukuran lahan } \\
\text { c. Aksesbilitas } \\
\text { d. Ketersedian } \\
\text { fasilitas }\end{array}$ & $\begin{array}{l}\text { Data Primer } \\
\text { dan Sekunder }\end{array}$ & $\begin{array}{l}\text { wawancara } \\
\text { kepada } \\
\text { stakeholder dan } \\
\text { survey di } \\
\text { lapangan }\end{array}$ \\
\hline 4. & $\begin{array}{l}\text { Aspek } \\
\text { Finansial }\end{array}$ & $\begin{array}{l}\text { a. Biaya investasi } \\
\text { b. Pendapatan } \\
\text { c. Pengeluaran } \\
\text { d. Aliran kas }\end{array}$ & $\begin{array}{l}\text { Data } \\
\text { Sekunder }\end{array}$ & $\begin{array}{l}\text { a. Market Research } \\
\text { Surabaya } \\
\text { b. PT. PLN } \\
\text { c. PDAM } \\
\text { d. Data pembanding }\end{array}$ \\
\hline 5. & $\begin{array}{l}\text { Produktifitas } \\
\text { maksimum }\end{array}$ & Nilai lahan & $\begin{array}{l}\text { Data } \\
\text { Sekunder }\end{array}$ & $\begin{array}{l}\text { Berdasarkan hasil } \\
\text { perhitungan aspek } \\
\text { finansial }\end{array}$ \\
\hline
\end{tabular}

\section{DISKUSI DAN PEMBAHASAN}

\section{A. Penentuan Alternatif}

Berdasarkan hasil penyebaran kuesioner kepada kepala pasar Blauran Surabaya dan penyewa kios Pasar Blauran didapatkan alternatif penggunaan lahan yaitu revitalisasi pasar, mixed use pasar dengan perbelanjaan dan mixed use pasar dengan perkantoran. Alternatif ini mempertimbangkan keberadaan pasar tanpa menghilangkan fungsi pasar

\section{B. Aspek Legal}

Berikut adalah data yang didapatkan dari Dinas Cipta Karya dan Tata Ruang Kota Surabaya mengenai building code dan keperuntukan lahan pada Pasar Blauran:

1) Keperuntukan Lahan sebagai Perdagangan dan Jasa

2) Garis Sempadan Bangunan untuk sisi depan (Jalan Kranggan) $6 \mathrm{~m}$, sisi kanan $6 \mathrm{~m}$, sisi belakang $6 \mathrm{~m}$ dan sisi kiri $4 \mathrm{~m}$

3) Koefisien Dasar Bangunan (KDB) maksimum $60 \%$

4) Koefisien Lantai Bangunan (KLB) maksimum $900 \%$

5) Koefisien Daerah Hijau (KDH) minimum $10 \%$

Berdasarkan hasil analisa pada aspek legal didapatkan luas dasar bangunan sebesar $3330 \mathrm{~m}^{2}$, jumlah lantai maksimum adalah 15 lantai dengan luas lantai bangunan maksimum $49950 \mathrm{~m}^{2}$.

\section{Aspek Fisik}

Analisa pada aspek fisik ini terdiri dari lokasi, bentuk lahan, aksesbilitas dan ketersediaan fasilitas. Setiap alternatif dianalisa untuk mengetahui apakah memungkinkan jika dibangun berdasarkan aspek fisik yang ada.

\section{1) Lokasi lahan}

Lahan ini berada di Jalan Kranggan Sawahan Surabaya, berada di dekat perempatan depan Bubutan Golden Junction. Lokasi ini termasuk lokasi yang stategis dan berada di tengah kota Surabaya. Lokasi dekat dengan pusat perdagangan dan jasa seperti Jalan Basuki Rachmat, Embong Malang, Bubutan dan Praban.

\section{Latar belakang}

Lokasi lahan yang terletak di tengah kota, strategis dan disekitar lahan yang sudah banyak berkembang menjadi properti komersil sedangkan kondisi pasar yang kurang nyaman dan sepi pengunjung

\section{$\checkmark$}

\section{Rumusan Masalah}

Bagaimana cara memperoleh alternatif penggunaan lahan tertingg dan terbaik dengan menggunakan analisa pada aspek legal, fisik, finansial dan produktivitas maksimum

\section{$\downarrow$}

Tinjauan Pustaka

Konsep penggunaan Tertinggi dan Terbaik (Highest and Best

Use), Konsep dan jenis properti dan Penelitian Terdahulu.

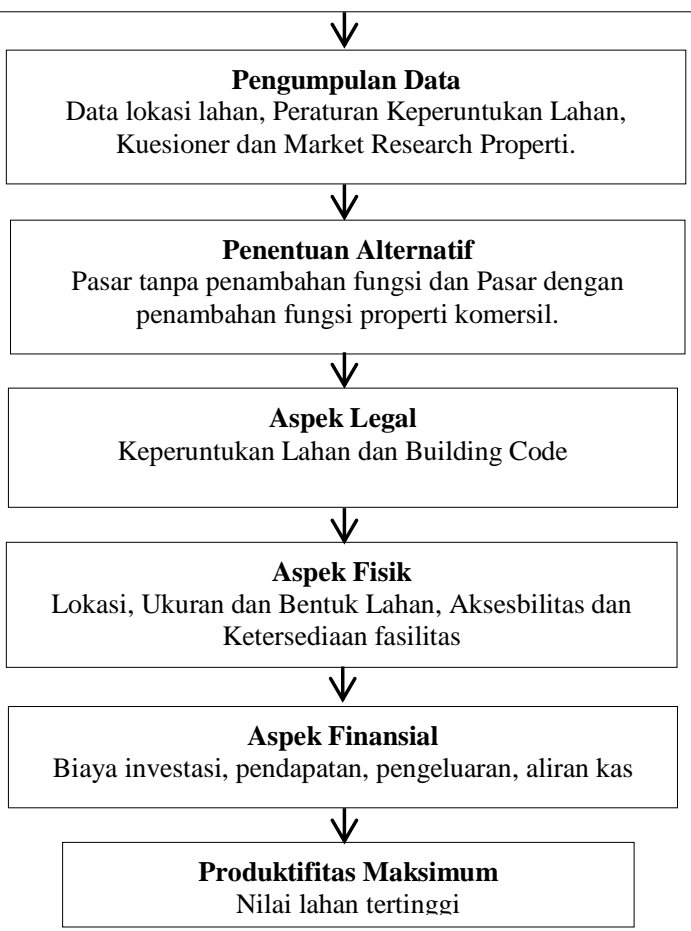

Gambar 1. Bagan Alir Penelitian.

\section{2) Ukuran dan Bentuk Lahan}

Lahan ini memiliki luasan $5550 \mathrm{~m}^{2}$, bentuk lahan yang tidak simetris dikarenakan bagian depan lahan yang berbatasan langsung dengan pertokoan pada Jalan Kranggan. Ukuran lahan dengan kurang lebih memiliki lebar $\pm 77 \mathrm{~m}$ dan panjang $\pm 73 \mathrm{~m}$ ini termasuk lahan yang cukup luas dan memungkinkan dijadikan revitalisasi pasar, perbelanjaan dan perkantoran. Hal ini dikarenakan alternatif tersebut membutuhkan lahan yang luas untuk dijadikan ruang sewa atau stan untuk disewakan.

3) Aksesbilitas

Lokasi lahan yang strategis, berada di tengah kota menjadikan lahan ini mudah untuk dijangkau dan diakses dari berbagai arah. Seperti dari arah Jalan Jalan Embong Malang, Jalan Tidar, Jalan Blauran, bahkan dari Jalan Bubutan. Alternatif revitalisasi pasar, perbelanjaan dan perkantoran membutuhkan aksesbilitas yang mudah dan dapat dijangkau dari berbagai arah. Oleh karena itu alternatif tersebut memungkinkan dari segi aksesbilitas 
4) Ketersediaan fasilitas

Berdasarkan wawancara kepada Kepala Pasar Blauran, lahan ini memiliki ketersediaan fasilitas seperti listrik, saluran air bersih, saluran telfon. Oleh karena itu ketersediaan fasilitas ini dapat menunjang untuk alternatif yang telah ditentukan.

Hasil analisa pada aspek fisik, maka alternatif revitalisasi pasar, perbelanjaan dan perkantoran memungkinkan untuk digunakan pada lahan Pasar Blauran, jika ditinjau dari kriteria lokasi, ukuran dan bentuk lahan, aksesbilitas dan ketersediaan fasilitas.

\section{D.Perencanaan Bangunan}

Perencanaan bangunan pada setiap alternatif ini meliputi desain bangunan dan kebutuhan area parkir yang dibutuhkan. Perencanaan bangunan pada revitalisasi pasar memiliki luas yang sama dengan kondisi eksisting pasa saat ini. Luas pasar Blauran saat ini adalah $11380 \mathrm{~m}^{2}$ dibagi dengan luas dasar bangunan yang diizinkan sesuai analisa aspek legal yaitu $3330 \mathrm{~m}^{2}$, maka didapatkan jumlah lantai untuk revitalisasi pasar adalah 4 lantai dan 1 lantai untuk parkir indoor. Alternatif mixed use pasar dan perbelanjaan memiliki 3 lantai untuk area parkir, 4 lantai difungsikan sebagai pasar dan 5 lantai sebagai perbelanjaan. Rencana jumlah 5 lantai untuk perbelanjaan ini berdasarkan beberapa perbelanjaan sekelas trade center di Surabaya menggunakan kurang lebih 5 lantai. Sedangkan pada alternatif mixed use pasar dengan perkantoran memiliki 3 lantai untuk parkir indoor, 4 lantai untuk pasar dan 8 lantai untuk perkantoran.

\section{E. Aspek Finansial}

Aspek finansial ini terdiri dari perhitungan biaya investasi, pendapatan, pengeluaran dan aliran kas. Dikarenakan lahan Pasar Blauran terdapat bangunan diatasnya dan direncanakan sebagai lahan kosong maka perlu adanya biaya pembongkaran bangunan.

\section{1) Biaya Investasi}

Biaya investasi ini terdiri dari biaya pembongkaran bangunan, biaya lahan, biaya bangunan, biaya kelengkapan bangunan, biaya jasa profesi dan biaya administrasi. Berdasarkan metode pendekatan data pasar, nilai lahan ini didapatkan dari beberapa nilai lahan yang berada di sekitar objek penelitian, didapatkan nilai lahan sebesar Rp $21.297 .649 / \mathrm{m}^{2}$. Berikut adalah rekapitulasi biaya investasi pada setiap alternatif.

Tabel 2.

Biaya Investasi

\begin{tabular}{|c|c|c|c|}
\hline \multirow[b]{2}{*}{ Uraian Biaya } & \multicolumn{2}{|c|}{ Blaya investasi } & \multirow[b]{2}{*}{$\begin{array}{c}\text { Mixed use } \\
\text { pasar dengan } \\
\text { perkantoran } \\
(\mathbf{R p})\end{array}$} \\
\hline & $\begin{array}{l}\text { Revitalisasi } \\
\text { Pasar (Rp) }\end{array}$ & $\begin{array}{c}\text { Mixed use } \\
\text { pasar dengan } \\
\text { perbelanjaan } \\
\quad(\mathbf{R p})\end{array}$ & \\
\hline $\begin{array}{l}\text { Biaya } \\
\text { pembongkaran }\end{array}$ & 1.248 .101 .500 & 1.248 .101 .500 & 1.248 .101 .500 \\
\hline Biaya lahan & 118.201 .954 .084 & 118.201 .954 .084 & 118.201 .954 .084 \\
\hline Biaya konstruksi & 70.036 .560 .000 & 205.221 .240 .000 & 276.877.276.916 \\
\hline $\begin{array}{l}\text { Biaya } \\
\text { kelengkapan } \\
\text { bangunan }\end{array}$ & 17.509 .140 .000 & 71.827.434.000 & 77.525.637.537 \\
\hline Biaya jasa profesi & 3.501 .828 .000 & 10.261 .062 .000 & 13.843 .863 .846 \\
\hline Biaya administrasi & 700.365 .600 & 2.052 .212 .400 & 2.768 .772 .769 \\
\hline $\begin{array}{l}\text { Total biaya } \\
\text { investasi }\end{array}$ & 211.197.949.184 & 408.812 .003 .984 & 490.465 .606 .652 \\
\hline
\end{tabular}

\section{2) Pendapatan}

Pendapatan ini terdiri dari biaya sewa, service charge dan pemasukan dari segi parkir. Biaya sewa didapatkan dari perbandingan data dengan properti sejenis yang ada di
Surabaya. Sedangkan service charge dibebankan kepada penyewa untuk membiayai biaya operasional. Besarnya service charge berbeda sesuai dengan masing-masing alternatif.

\section{3) Pengeluaran}

Pengeluaran pada tiap alternatif terdiri dari biaya operasional dan biaya pemeliharaan bangunan. biaya operasional terdiri dari biaya listrik, air dan gaji pegawai. Biaya listrik dan air disesuaikan dengan tarif dasar listrik dan tarif air yang berlaku di Surabaya.

4) Aliran Kas

Selisih antara pendapatan dan pengeluaran tiap tahun digambarkan dalam bentuk aliran kas guna mengetahui pendapatan bersih tiap tahunnya. Layak tidaknya suatu alternatif dianalisa menggunakan uji kelayakan berupa NPV. Nilai NPV lebih besar dari nol maka alternatif tersebut dapat dikatakan layak.

Berdasarkan analisa pada aspek finansial didapatkan nilai NPV pada alternatif revitalisasi pasar sebesar Rp 41.945.262.744, alternatif mixed use pasar dengan perbelanjaan sebesar Rp 387.270.382.103, sedangkan NPV pada alternatif mixed use pasar dengan perkantoran sebesar Rp 346.367.347.187.

\section{F. Produktifitas Maksimum}

Alternatif yang telah dianalisa dan layak pada aspek legal, fisik dan finansial selanjutnya dianalisa menggunakan produktifitas maksimum. Nilai produktifitas maksimum dari setiap alternatif dapat diketahui dengan menghitung nilai lahan. Nilai lahan dengan nilai tertinggi merupakan alternatif dengan produktifitas maksimum. Perhitungan nilai lahan pada setiap alternatif dapat dilihat pada Tabel 3 .

Tabel 3.

\begin{tabular}{|c|c|c|c|c|}
\hline \multirow[b]{2}{*}{ No. } & \multicolumn{4}{|c|}{ Perhitungan Produktifitas Lahan } \\
\hline & Uraian & $\begin{array}{c}\text { Revitalisasi } \\
\text { Pasar }\end{array}$ & $\begin{array}{l}\text { Mixed use pasar } \\
\text { dengan } \\
\text { perbelanjaan }\end{array}$ & $\begin{array}{c}\text { Mixed use pasar } \\
\text { dengan } \\
\text { perkantoran }\end{array}$ \\
\hline 1. & Nilai Properti & 135.989 .281 .700 & 687.851 .654 .804 & 729.272 .285 .310 \\
\hline 2. & Biaya Investasi & 211.197 .949 .184 & 408.812 .003 .984 & 490.465 .606 .652 \\
\hline 3. & Biaya Tanah & 118.201 .954 .084 & 118.201 .954 .084 & 118.201 .954 .084 \\
\hline 4. & Nilai Bangunan & 92.995 .995 .100 & 290.610 .049 .900 & 372.263 .652 .568 \\
\hline 5. & Nilai Lahan & 42.993 .286 .600 & 397.241 .604 .904 & 357.008 .632 .742 \\
\hline 6. & Nilai lahan $/ \mathrm{m}^{2}$ & 7.746 .538 & 71.575 .064 & 64.325 .880 \\
\hline 7. & $\begin{array}{l}\text { Harga lahan } \\
\text { awal } / \mathrm{m}^{2}\end{array}$ & 21.297 .649 & 21.297 .649 & 21.297 .649 \\
\hline 8. & Produktifitas & $-63,63 \%$ & $236,07 \%$ & $202,03 \%$ \\
\hline
\end{tabular}

\section{KESIMPULAN}

Berdasarkan hasil analisa dan perhitungan, lahan pasar Blauran seluas $5550 \mathrm{~m}^{2}$ ini dapat digunakan sebagai pasar dengan penambahan properti komersil dengan luas dasar bangunan sebesar $3330 \mathrm{~m}^{2}$, jumlah lantai maksimum 15 lantai dan luas lantai bangunan sebesar $49950 \mathrm{~m}^{2}$.

Alternatif yang memenuhi pada aspek legal, fisik dan finansial adalah revitalisasi pasar, mixed use pasar dengan perbelanjaan dan mixed use pasar dengan perkantoran. Dari ketiga alternatif didapatkan alternatif mixed use pasar dengan perbelanjaan merupakan alternatif penggunaan tertinggi dan terbaik. nilai lahan alternatif ini sebesar Rp 71.575.064 dari nilai lahan semula $\mathrm{Rp}$ 21.297.649. Kenaikan nilai lahan ini merupakan produktifias pada lahan yaitu sebesar $236,07 \%$. 


\section{DAFTAR PUSTAKA}

[1] Hidayati, W dan Harjanto, B. 2003. Konsep Dasar Penilaian Properti. BPFE : Yogyakarta.

[2] Mubbayinah, M dan Utomo, C. 2012. Analisa Highest and Best Use (HBU) Lahan " $X$ " Untuk Properti Komersial. Jurnal Teknik ITS Vol.1, No1, hal. D-16-D19

[3] Aziz, C N dan Utomo, C. 2015. Analisa Highest and Best Use pada Lahan Gedung Serbaguna Purnama di Jl. R.A Kartini Bangkalan. Jurnal Teknik ITS Vol. 4, No.1, hal D51-D53.

[4] Rasyid, T D A dan Utomo, C. 2013. Analisa Highest and Best Use $(H B U)$ pada lahan Bekas SPBU Biliton Surabaya. Jurnal Teknik ITS Vol.2, No. 2, hal. D181-D185.

[5] Akmaluddin dan Utomo, C. 2013. Analisa Highest and Best Use (HBU) pada lahan Jl. Gubeng Raya No.54 Surabaya. Jurnal Teknik POMITS Vol. 2, No.1, hal C6- C10.

[6] Satiti, R. 2011. Analisa Highest and Best Use pada Lahan Trillium Office and Residence-Surabaya. Tugas Akhir Program Studi Teknik Sipil. Surabaya : FTSP - ITS

[7] Juwana, J. S. 2005. Panduan Sistem Bangunan Tinggi. Jakarta: Erlangga.

[8] Poerbo, H. 1998. Tekno Ekonomi Bangunan Bertingkat Banyak. Jakarta: Djambatan.

[9] PIPU, 2016. Pusat Informasi Pasar Uang. Bank Indonesia

[10] Peraturan Menteri Pekerjaan Umum No 45/PRT/M/2007 tentang Pedoman Teknis Pembangunan Bangunan Gedung Negara.

[11] Peraturan Walikota Surabaya No. 57 Tahun 2015 tentang Pedoman Teknis Pengendalian Pemanfaatan Ruang Dalam Rangka Pendirian Bangunan Di Kota Surabaya

[12] Peraturan Daerah Kota Surabaya No. 3 Tahun 2007 tentang Rencana Tata Ruang Wilayah Kota Surabaya

[13] Soeharto, I. 1995. Manajemen Proyek. Jakarta : Erlangga. 